Original Article

\title{
A content analysis of stroke physical therapy intervention using stroke physiotherapy intervention recording tool
}

\author{
Hyuk-shin Cho, PT, PhD ${ }^{1)}$, Hyun-Gyu Cha, PT, PhD²* \\ 1) Department of Physical Therapy, Wonkwang Health Science University, Republic of Korea \\ 2) Department of Physical Therapy, College of Kyungbuk: 77 Daehak-ro, Yeongju, Gyeongsangbuk-do \\ 750-712, Republic of Korea
}

\begin{abstract}
Purpose] Physical therapy for recovery of function in people with stroke is known to be effective, but which type of physical therapy intervention is most effective is uncertain because a concrete and detailed record of interventions is done. This study aimed to record, analyze, and describe the content of physical therapy interventions for recovery of function after stroke using stroke physiotherapy intervention recording tool (SPIRIT). [Subjects and Methods] A convenience sample of 23 physical therapists from a rehabilitation hospital in Chung-nam recorded the interventions for 73 patients with stroke who were treated for 30 minutes in 670 treatment sessions. Treatment session contents were recorded using SPIRIT. Descriptive statistics were used to describe the interventions accurately and to investigate the differences according to time since stroke. [Results] Facilitation techniques were the most frequently used interventions $(n=1,342,35.1 \%)$, followed by practice $(n=1,056,27.6 \%)$, and exercise $(\mathrm{n}=748,19.6 \%)$ in the physical therapists' clinical practice. [Conclusion] This pattern shows that physical therapists were focused on functional activity. Organizing or teaching patient activities for independent practice interventions $(n=286,7.5 \%)$ were used to encourage patient activity and independence outside the treatment sessions. Interventions according to time since stroke were not significantly different.

Key words: Physiotherapy, SPIRIT, Stroke rehabilitation
\end{abstract}

(This article was submitted Dec. 17, 2015, and was accepted Feb. 2, 2016)

\section{INTRODUCTION}

The objective of rehabilitation for stroke patients is to restore normal function and improve quality of life ${ }^{1)}$. While it is known that physiotherapy can be effective for rehabilitation of stroke patients, it is not clear what type of physiotherapy is most effective ${ }^{1)}$. Physiotherapy is a technical interaction between therapists and patients for a specific purpose. It is process implemented and modified to achieve a mutually agreed objective. The process involves the application of physical, therapeutic-electrical, and motional methods. Additionally, aids are used for functional training, and counseling/training is provided to patients ${ }^{1}$. To restore function in stroke patients, effective physiotherapy interventions based on evidence are of utmost importance. While various forms of physiotherapy interventions are used, there is no system for recording them in a standardized format ${ }^{2}$. Such lack of data is one of the critical factors that hinder evidence-based treatment ${ }^{3}$. Accurate and concrete data on physiotherapy interventions are crucial to making evidence-based research possible. Stroke Physiotherapy Intervention Recording Tool (SPIRIT) was developed to address this problem. It is a recording system for physiotherapy interventions for stroke patients ${ }^{3)}$. SPIRIT can accurately record interventions such as balanced sitting, balanced standing, or walking, which are interventions used by physiotherapists to correct posture problems. This can assist physiotherapists in conducting effective interventions ${ }^{4}$. Typical physiotherapy interventions used for stroke patients in Korea include bobath,

\footnotetext{
*Corresponding author. Hyun-gyu Cha (E-mail: niceguy-chatty@hanmail.net)

(C)2016 The Society of Physical Therapy Science. Published by IPEC Inc.

This is an open-access article distributed under the terms of the Creative Commons Attribution Non-Commercial No Derivatives (by-nc-nd) License $<$ http://creativecommons.org/licenses/by-nc-nd/4.0/>.
} 
neurodevelopmental treatment (NDT), and proprioceptive neuromuscular facilitation (PNF) ${ }^{5,6}$. The objective of the current study was to accurately record and analyze physiotherapy interventions for stroke patients using SPIRIT, and, thus, help patients choose effective interventions for functional recovery in clinical settings.

\section{SUBJECTS AND METHODS}

Participants who met the inclusion criteria and agreed to participate in the study received a general explanation of the study, and gave their written informed consent. All procedures were reviewed and approved by the Institutional Ethics Committee of Eulji University Hospital. A total of 23 physiotherapists and 73 stroke patients participated in the study. Physiotherapists received training on how to record SPIRIT 6 hours a day for a 3-day period. Only therapists with 5 years of clinical experience and central nervous system treatment certificates were selected. Therapists conducted physiotherapy interventions for 30 minutes a day 5 times a week for 1 week, and recorded them with SPIRIT. Characteristics of the therapists and patients who participated in the research are listed in Table 1. Data collected were recorded and statistically analyzed using SPSS 18.0. Frequency analysis was conducted to identify participants for research and methods of physiotherapy intervention.

\section{RESULTS}

A total of 3,824 interventions were recorded. Physiotherapy interventions used are indicated in Tables 2 and 3 . The analysis of physiotherapy interventions for rehabilitation of stroke patients identifies the use of interventions such as facilita-

Table 1. General and medical characteristics of participants $(\mathrm{N}=73)$

\begin{tabular}{|c|c|c|}
\hline & & Stroke patient \\
\hline \multicolumn{2}{|c|}{ Gender (male/female) } & $36 / 37$ \\
\hline \multicolumn{2}{|l|}{ Age (years) } & $65.2 \pm 8.6^{\mathrm{a}}$ \\
\hline \multicolumn{2}{|l|}{ Height $(\mathrm{cm})$} & $165.8 \pm 4.1$ \\
\hline \multicolumn{2}{|l|}{ Weight $(\mathrm{kg})$} & $64.5 \pm 5.4$ \\
\hline \multicolumn{2}{|c|}{ Causes (infarction/hemorrhage) } & $40 / 33$ \\
\hline \multicolumn{2}{|c|}{ Affected side (right /left) } & $34 / 39$ \\
\hline \multicolumn{2}{|c|}{ Since onset (months) } & $2.2 \pm 1.1$ \\
\hline \multicolumn{2}{|c|}{ Modified Ashworth Scale (G0/G1/G1+) } & $20 / 43 / 10$ \\
\hline \multirow[t]{3}{*}{ Stages } & Acute & 1 \\
\hline & Rehabilitation & 70 \\
\hline & Pre-discharge & 2 \\
\hline \multirow[t]{3}{*}{ Aims of treatment } & Sitting balance & 13 \\
\hline & Standing balance & 12 \\
\hline & Walking & 48 \\
\hline
\end{tabular}

${ }^{\mathrm{a}} \mathrm{mean} \pm \mathrm{SD}$

Table 2. Intervention frequencies $(\mathrm{N}=3,824)$

\begin{tabular}{lccc}
\hline Intervention & Total & $\begin{array}{c}\text { Sitting } \\
\text { balance }\end{array}$ & $\begin{array}{c}\text { Standing } \\
\text { balance }\end{array}$ \\
\hline Facilitation & $1,342^{\mathrm{a}}\left(35.1^{\mathrm{b}}\right)$ & $200(42.2)$ & $192(44.5)$ \\
Whole activities & $870(22.8)$ & $224(22.4)$ & $252(28.6)$ \\
Components of activities & $472(12.3)$ & $94(19.8)$ & $79(9.0)$ \\
Practice & $1,056(27.6)$ & $24(5.1)$ & $109(25.2)$ \\
Whole activities & $794(20.8)$ & $14(3.0)$ & $151(17.2)$ \\
Components of activities & $262(6.9)$ & $10(2.1)$ & $80(9.1)$ \\
Exercise & $748(19.6)$ & $95(20.0)$ & $65(15.0)$ \\
Organizing or teaching patient activities independent practice & $286(7.5)$ & $30(6.3)$ & $20(4.6)$ \\
Mobilization & $193(5.0)$ & $68(14.3)$ & $10(2.3)$ \\
Other activities & $117(3.1)$ & $50(10.5)$ & $27(6.3)$ \\
Provision of or training on the use of equipment & $70(1.8)$ & $0(0.0)$ & $9(2.1)$ \\
Teaching activities for support staff and/or health care professionals to perform/assist & $12(0.3)$ & $7(1.5)$ & $0(0.0)$ \\
\hline
\end{tabular}

${ }^{a} \mathrm{~N}$ : number of persons, ${ }^{\mathrm{b}} \%$ : percent 
Table 3. Detailed intervention frequencies $(N=3,824)$

\begin{tabular}{|c|c|}
\hline Iintervention & Total $\left(\mathrm{N}^{\mathrm{a}}\right)$ \\
\hline Facilitation & 1,342 \\
\hline Whole activities & 870 \\
\hline Walking with aids & 178 \\
\hline Walking with help & 127 \\
\hline Dynamic standing & 94 \\
\hline Movement of the leg & 71 \\
\hline Movement of the arm & 66 \\
\hline Dynamic sitting & 60 \\
\hline Free walking & 55 \\
\hline Static sitting & 53 \\
\hline Sit-to-stand & 46 \\
\hline Outdoor mobility & 39 \\
\hline Static standing & 27 \\
\hline Bed mobility & 17 \\
\hline Stairs & 12 \\
\hline Transfers & 5 \\
\hline Falls routine & 0 \\
\hline Components of activities & 472 \\
\hline Movement of the leg & 136 \\
\hline Sit-to-stand & 96 \\
\hline Walking & 69 \\
\hline Movement of the arm & 50 \\
\hline Standing & 46 \\
\hline Sitting & 30 \\
\hline Mobility & 24 \\
\hline Transfer & 10 \\
\hline Stairs & 7 \\
\hline Falls routine & 4 \\
\hline Practice & 1,056 \\
\hline Whole activities & 794 \\
\hline Walking with aids & 182 \\
\hline Outdoor mobility & 164 \\
\hline Free walking & 162 \\
\hline Dynamic standing & 67 \\
\hline Walking with help & 42 \\
\hline Sit-to-stand & 41 \\
\hline Dynamic sitting & 29 \\
\hline Static standing & 25 \\
\hline Treadmill & 22 \\
\hline Stairs & 21 \\
\hline Movement of the arm & 19 \\
\hline Movement of the leg & 13 \\
\hline Bed mobility & 5 \\
\hline Falls routine & 2 \\
\hline Static sitting & 0 \\
\hline Transfer & 0 \\
\hline Wheelchair skills & 0 \\
\hline Components of activities & 262 \\
\hline Walking & 83 \\
\hline Sit-to-stand & 42 \\
\hline Movement of the leg & 38 \\
\hline Stairs & 29 \\
\hline
\end{tabular}

\begin{tabular}{|c|c|}
\hline Iintervention & Total $\left(\mathrm{N}^{\mathrm{a}}\right)$ \\
\hline Movement of the arm & 18 \\
\hline Bed mobility & 17 \\
\hline Transfers & 15 \\
\hline Wheelchair skills & 12 \\
\hline Sitting & 8 \\
\hline Standing & 0 \\
\hline Falls routine & 0 \\
\hline Exercise & 748 \\
\hline Strengthening exercise & 363 \\
\hline Stretching exercise & 295 \\
\hline Resisted exercise & 62 \\
\hline Cardiovascular fitness exercise & 28 \\
\hline $\begin{array}{l}\text { Organizing, or teaching, patient activities } \\
\text { for independent practice }\end{array}$ & 286 \\
\hline Sit-to-stand & 87 \\
\hline Walking indoors & 57 \\
\hline Stretching exercise & 51 \\
\hline Strengthening exercise & 39 \\
\hline Bed mobility & 27 \\
\hline Outdoor mobility & 10 \\
\hline Transfer & 9 \\
\hline Cardiovascular exercise & 6 \\
\hline Resisted exercise & 0 \\
\hline Stairs & 0 \\
\hline Mobilization & 193 \\
\hline Shoulder girdle mobilization & 79 \\
\hline Trunk mobilization & 47 \\
\hline Specific joint mobilization & 45 \\
\hline Specific muscle mobilization & 22 \\
\hline Other activities & 117 \\
\hline Gym ball & 56 \\
\hline Postural perturbations & 36 \\
\hline Sensory stimulation & 25 \\
\hline Other & 0 \\
\hline $\begin{array}{l}\text { Providing equipment, or training the patient } \\
\text { in the use of }\end{array}$ & 70 \\
\hline Walking aids & 48 \\
\hline Ankle foot orthosis & 12 \\
\hline Other splints & 5 \\
\hline Wheelchair skills & 5 \\
\hline Transfer equipment & 0 \\
\hline $\begin{array}{l}\text { Teaching activities for support staff and/or } \\
\text { hcps to perform/assist }\end{array}$ & 12 \\
\hline Positioning & 7 \\
\hline Walking indoors & 3 \\
\hline Outdoor mobility & 2 \\
\hline Stretching exercise & 0 \\
\hline Bed mobility & 0 \\
\hline Transfers & 0 \\
\hline Stairs & 0 \\
\hline Wheelchair skills & 0 \\
\hline Use of manual handling equipment & 0 \\
\hline Use of ankle foot orthosis / splints & 0 \\
\hline
\end{tabular}


tion $(n=1,342,35.1 \%)$, practice $(n=1,056,27.6 \%)$, exercise $(n=748,19.6 \%)$, the organizing or teaching of patient activities for independent practice $(n=286,7.5 \%)$, mobilization $(n=193,5.0 \%)$, other activities $(n=117,3.1 \%)$, training on the use of equipment ( $\mathrm{n}=70,1.8 \%$ ), and teaching activities for support staff and/or healthcare professionals (HC) to perform/assist $(\mathrm{n}=12,0.3 \%)$. The analysis of 90 sub-items of physiotherapy interventions indicates the use of the following physiotherapy interventions. In the 'facilitation' category, 'walking with aids' as a whole activity and 'movement of the leg' as a component of an activity were used. In the 'practice' category, 'walking with aids' as a whole activity and 'walking' as a component of an activity were used. In the 'exercise' category, 'strengthening exercise' and 'sit-to-stand' were used in the category of 'organizing of teaching patient activities for independent practice'. In the 'mobilization' category, shoulder girdle mobilization was used. In the 'other activities' category, gym ball was used. In the category of 'providing equipment or training patients in the use of equipment', 'walking aids', 'teaching activities for support staff and/or HCPs to perform/assist' were used. Furthermore, in the 'assist' category, the analysis found positioning was used.

\section{DISCUSSION}

It has been found that SPIRIT is helpful in recording and analyzing physiotherapy interventions for stroke patients. This analysis of physiotherapy intervention using SPIRIT shows that facilitation and practice are used frequently to assist functional recovery. Facilitation is intended to improve specific movements of the patients, and requires patients to move passively or actively with force applied by physical therapists. This includes whole activities as well as their individual components. 'Practice' requires patients to move actively under the supervision of the therapist. It also includes whole activities and their components. This exercise category includes stretching, muscle enhancement, resistance, and heart and lung exercise. The organizing of teaching patient activities or activities for independent practice are modes of training intended to enable the performance of special exercise or functional activities for patients with the supervision of healthcare experts. 'Mobilization' is a type of manual therapy that moves the spine, shoulder blades, pelvis, and joints in the body for the purpose of normalizing muscle tightness. Other activities include those that are not clearly specified such as gym ball exercise or sense stimulation. Provision of or training on the use of equipment indicates the application of below-knee orthosis, splints, and walking aids. The 'teaching activities for support staff and/or HCPs to perform/assist with' category includes teaching home exercise or precautions to help in the functional recovery of patients. The findings of the current study show that facilitation and practice constitute $62.7 \%$ of all physical therapy interventions. This indicates that activities and task-oriented approaches, which are the latest trends in physiotherapy intervention, are used. In particular, the findings reveal the use of the following physiotherapy interventions: 'walking with aids', 'walking with help', and 'dynamic standing' in whole activities, 'movement of the leg' and 'sit-to-stand' in components of activities, and 'walking with aids', 'outdoor mobility', and 'free walking' in whole activities. This result seems to be related to the fact that the goal of 48 out of the 73 patients $(66 \%)$ was to walk. It also shows that the right interventions in achieving this goal were utilized. Previous study shows few instances of using strengthening or stretching exercises to normalize muscle tightness and improve the quality of movement ${ }^{7}$. However, the current study has yielded results that are contrary to that of the previous study. Previous physiotherapy interventions did not focus on muscle strengthening exercise for the purpose of reducing abnormal muscle tightness ${ }^{8}$. Currently, muscle strengthening exercises are used to prevent stiffness and contracture of joints, and alleviate muscle tightness. Teaching activities for support staff and/or HCPs to perform/assist with was performed minimally, recording a mere $0.3 \%$. This shows that although it is an important exercise to help restore the independent function of patients, it is largely neglected. It is because most patients receive assistance in a group given the particular characteristics of hospital environments, rather than in a one-on-one setting. Limitations of the current study lie in the fact that physiotherapy interventions for stroke patients were recorded in a single rehabilitation hospital in Korea. Therefore, it is difficult to generalize the findings for all stroke patients.

\section{ACKNOWLEDGEMENT}

This study was supported by Wonkwang Health Science University in 2016.

\section{REFERENCES}

1) Langhorne P, Wagenaar R, Partridge C: Physiotherapy after stroke: more is better? Physiother Res Int, 1996, 1: 75-88. [Medline] [CrossRef]

2) Marsden J, Greenwood R: Physiotherapy after stroke: define, divide and conquer. J Neurol Neurosurg Psychiatry, 2005, 76: 465-466. [Medline] [CrossRef]

3) Tyson SF, Selley A: The development of the stroke physiotherapy intervention recording tool (SPIRIT). Disabil Rehabil, 2004, 26: 1184-1188. [Medline] [CrossRef]

4) Donaldson C, Tallis RC, Pomeroy VM: A treatment schedule of conventional physical therapy provided to enhance upper limb sensorimotor recovery after stroke: expert criterion validity and intra-rater reliability. Physiotherapy, 2009, 95: 110-119. [Medline] [CrossRef]

5) Cha HK, Ji SG, Kim MK, et al.: Effect of transcranial direct current stimulation of function in patients with stroke. J Phys Ther Sci, 2014, 26: 363-365. [Medline] [CrossRef] 
6) Ji SG, Cha HG, Kim MK, et al.: The effect of mirror therapy integrating functional electrical stimulation on the gait of stroke patients. J Phys Ther Sci, 2014, 26: 497-499. [Medline] [CrossRef]

7) Tyson S, Selley A: A content analysis of physiotherapy for postural control in people with stroke: an observational study. Disabil Rehabil, 2006, 28: 865-872. [Medline] [CrossRef]

8) Sommerfeld DK, Eek EU, Svensson AK, et al.: Spasticity after stroke: its occurrence and association with motor impairments and activity limitations. Stroke, 2004, 35: 134-139. [Medline] [CrossRef] 